Article

\title{
Amorphous Li-Al-Based Compounds: A Novel Approach for Designing High Performance Electrode Materials for Li-Ion Batteries
}

Franziska Thoss ${ }^{1,2, *}$, Lars Giebeler ${ }^{1,2}$, Jürgen Thomas ${ }^{1}$, Steffen Oswald ${ }^{1}$, Kay Potzger ${ }^{3}$, Helfried Reuther ${ }^{3}$, Helmut Ehrenberg ${ }^{4}$ and Jürgen Eckert ${ }^{1,2}$

1 Leibniz Institute for Solid State and Materials Research Dresden (IFW), Institute for Complex Materials, Helmholtzstr. 20, D-01069 Dresden, Germany;

E-Mails: 1.giebeler@ifw-dresden.de (L.G.); j.thomas@ifw-dresden.de (J.T.);

s.oswald@ifw-dresden.de (S.O.); j.eckert@ifw-dresden.de (J.E.)

2 Institute of Materials Science, TU Dresden, Helmholtzstr. 7, D-01069 Dresden, Germany

3 Helmholtz-Zentrum Dresden-Rossendorf (HZDR), Bautzner Landstraße 400, D-01314 Dresden, Germany; E-Mails: k.potzger@hzdr.de (K.P.); h.reuther@hzdr.de (H.R.)

4 Karlsruhe Institute of Technology (KIT), Institute for Applied Materials-Energy Storage Systems (IAM-ESS), Hermann-von-Helmholtz-Platz 1, D-76334 Eggenstein-Leopoldshafen, Germany; E-Mail: helmut.ehrenberg@kit.edu

* Author to whom correspondence should be addressed; E-Mail: f.thoss@ifw-dresden.de; Tel.: +49-351-4659-694; Fax: +49-351-4659-452.

Received: 14 October 2013; in revised form: 6 November 2013 / Accepted: 7 November 2013 / Published: 18 November 2013

\begin{abstract}
A new amorphous compound with the initial atomic composition $\mathrm{Al}_{43} \mathrm{Li}_{43} \mathrm{Y}_{6} \mathrm{Ni}_{8}$ applied as electrode material for Li-ion batteries is investigated. Unlike other amorphous compounds so-far investigated as anode materials, it already contains $\mathrm{Li}$ as a base element in the uncycled state. The amorphous compound powder is prepared by high energy ball milling of a master alloy. It shows a strongly enhanced specific capacity in contrast to amorphous alloys without $\mathrm{Li}$ in the initial state. Therewith, by enabling a reversible (de)lithiation of metallic electrodes without the phase transition caused volume changes it offers the possibility of much increased specific capacities than conventional graphite anodes. According to the charge rate (C-rate), the specific capacity is reversible over 20 cycles at minimum in contrast to conventional crystalline intermetallic phases failing by volume changes. The delithiation process occurs quasi-continuously over a voltage range
\end{abstract}


of nearly $4 \mathrm{~V}$, while the lithiation is mainly observed between $0.1 \mathrm{~V}$ and $1.5 \mathrm{~V}$. That way, the electrode is applicable for different potential needs. The electrode stays amorphous during cycling, thus avoiding volume changes. The cycling performance is further enhanced by a significant amount of Fe introduced as wear debris from the milling tools, which acts as a promoting element.

Keywords: high energy ball milling; pre-lithiation; anode; intermetallic phase

\section{Introduction}

Intermetallic alloys are promising candidates as alternative anode materials with enhanced specific capacities in contrast to state-of-the-art techniques, which are dominated by carbon materials [1]. Disadvantageously, the phase transitions during the charge-discharge processes, induced by the (de)lithiation, cause volume changes of $100 \%-300 \%$ [2]. Due to the brittleness of intermetallic phases, the fracturing of the electrode material leads to loss of electrical contact. Since this circumstance forms a significant obstacle for an application as electrode material, intense efforts have been made to turn intermetallic phases suitable for high energy Li-ion batteries. Publications of comprehensively established approaches like nano-scaled materials, composites with buffering inactive matrices and thin film layers mark the latest examples of extensively investigated research fields [3-5]. Alternatively, amorphous alloys are also of great interest due to the absence of a long-range order. Amongst two marketable battery types, several current studies argue that the lithiation of amorphous alloys is possible [6,7]. Those are e.g., about composites, thin films, nanoscale thin films and coated particles [8-12]. Yet, the mechanism of Li-migration through a bulk amorphous framework is not completely clarified. With the intention to elucidate the lithiation mechanism in amorphous alloys further conventional amorphous Al-based alloys $\left(\mathrm{Al}_{86} \mathrm{Ni}_{8} \mathrm{Y}_{6}\right.$ and $\left.\mathrm{Al}_{86} \mathrm{Ni}_{8} \mathrm{La}_{6}\right)$ were investigated [13]. Realizing the lithiation process without a phase transformation would help to overcome the huge volume changes of intermetallic alloys. However, no remarkable specific capacity was observed. The main origin for this inefficiency is attributed to the rather low free volume, which describes the interstitial-like space between the host atoms of the amorphous material, of such Al-rich amorphous phase. This interstitial-like space is necessary to allow for sufficient Li migration into the amorphous host compound. An increase of the free volume by changing and optimizing milling parameters or addition of other elements is hardly possible. Indeed, additional free volume can be created by compositional tuning, i.e., by incorporating an additional element with different atomic radius such as to tune the atomic packing density and the short-range order of the amorphous phase [14-17].

It shall be noted that $\mathrm{Li}$ has a slightly larger atomic radius than $\mathrm{Al}$. The maximal free volume achieved by the selection of glass-forming elements and Al forms interstitial-like spaces, which are always smaller than the atomic radius of Li. An optimization of the free volume by glass-forming elements seems to be unsuitable for this reason. In contrast, after the electrochemical removal of $\mathrm{Li}$, voids and a skeleton-like host may remain. Following this line of thought, free volume in the Al-Y-Ni master alloy should be created by the incorporation of Li (Figure 1). The challenge of this approach is to deal with the unavoidable evaporation of Li during all melting processes. With high energy ball 
milling, we have chosen a method where the original Li content is preserved while amorphous compounds are prepared. Our work reports on the synthesis and the electrochemical performance of a new Li-containing amorphous compound with the composition $\mathrm{Al}_{43} \mathrm{Li}_{43} \mathrm{Y}_{6} \mathrm{Ni}_{8}$ (at.\%). With the concept of pre-alloying Li into the master alloy, we achieved a considerable increase of the specific capacity in contrast to Li-free amorphous alloys. Therewith, the difficulty of the volume changes within intermetallic alloys during electrochemical cycling is overcome. The promoting effect of $\mathrm{Fe}$ on the electrochemical performance is highlighted.

Figure 1. Schematic illustration of the lithiation processes within crystalline Al (upper row), the conventional, amorphous compound $\mathrm{Al}_{86} \mathrm{Y}_{6} \mathrm{Ni}_{8}$ (middle row) and the new amorphous alloy $\mathrm{Al}_{43} \mathrm{Li}_{43} \mathrm{Y}_{6} \mathrm{Ni}_{8}$ (lower row).
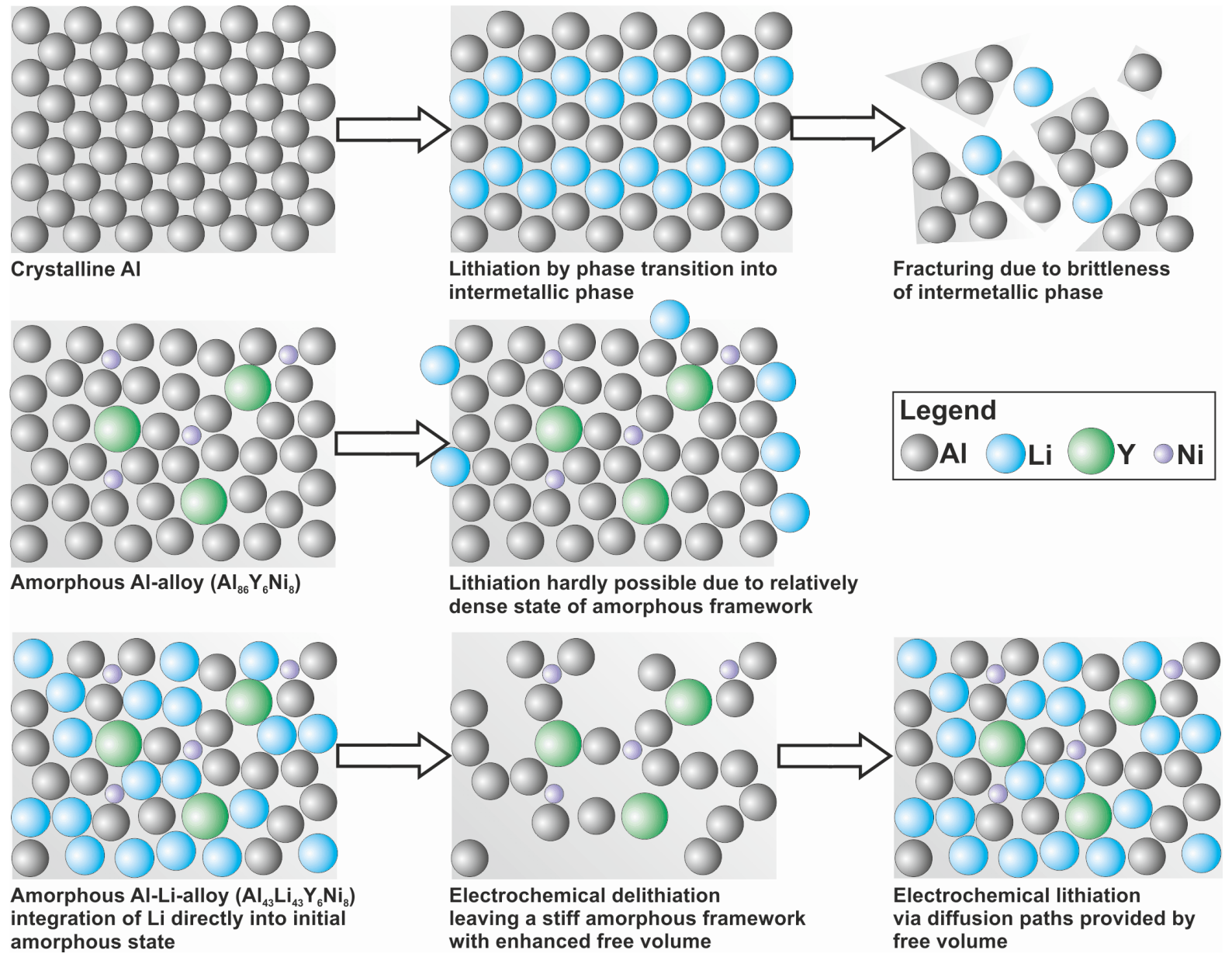

\section{Results and Discussion}

\subsection{Structural Characterization}

Amorphous $\mathrm{Al}_{43} \mathrm{Li}_{43} \mathrm{Y}_{6} \mathrm{Ni}_{8}$ powders ( $\mathrm{P} 1$ and $\mathrm{P} 2$ ), ball-milled in different vials, were chemically analyzed. Table 1 shows the element concentrations of the composition as well as additional constituent parts of $\mathrm{Fe}, \mathrm{O}$ and $\mathrm{N}$ introduced upon milling through unavoidable wear of the milling tools and powder contamination despite the use of the protective Ar milling atmosphere. The values of $\mathrm{O}$ and $\mathrm{N}$ are given with reservation due to the high amount of $\mathrm{Li}$, which sprinkles during melting. This 
behavior might cause the circumstance that the analyzed elements could not be summarized to $100 \%$. For this reason, the amounts of $\mathrm{O}$ and $\mathrm{N}$ were not analyzed separately by carrier gas hot extraction for powder P2. Fe was brought into powder P1 due to abrasive particles of the milling vials and balls. In order to improve the milling conditions by avoiding abrasive particles the steel vial was replaced by a silicon nitride vial, which is characterized by an extremely low abrasion due to the high hardness of $\mathrm{Si}_{3} \mathrm{~N}_{4}$. Chemical analysis of the material P2 from the silicon nitride vial reveals that this powder does not contain any $\mathrm{Fe}$, but traces of Si. Nevertheless, a high non-metallic content again occurred, similar as observed for the powder milled in steel vials.

Table 1. Chemical composition of amorphous and annealed $\mathrm{Al}_{43} \mathrm{Li}_{43} \mathrm{Ni}_{8} \mathrm{Y}_{6}$ powders. Since the amount of elements in wt.\% cannot be summarized to $100 \%$, it is not possible to give the amount in at.\%. The standard deviation is $0.3 \mathrm{wt} . \%$.

\begin{tabular}{cccc}
\hline \multirow{2}{*}{ Element } & Theoretical composition & Powder P1 (steel vial) & $\begin{array}{c}\text { Powder P2 (silicon } \\
\text { nitride vial) }\end{array}$ \\
\cline { 2 - 4 } & Amount [wt.\%] & Amount [wt.\%] & Amount [wt.\%] \\
\hline $\mathrm{Al}$ & 47.13 & 27.08 & 31.4 \\
$\mathrm{Li}$ & 12.12 & 8.82 & 9.3 \\
$\mathrm{Ni}$ & 19.07 & 11.13 & 11.7 \\
$\mathrm{Y}$ & 21.67 & 7.37 & 11.2 \\
$\mathrm{Fe}$ & - & 15.42 & traces \\
$\mathrm{Si}$ & - & - & 0.8 \\
$\mathrm{~S}$ & 100 & 69.82 & 64.4 \\
\hline
\end{tabular}

Analysis of the crystallinity of the milled compounds was performed by XRD (X-ray diffractometry) before and after cycling and by DSC (Figure 2a,b). The XRD patterns show very low intensities of broad reflections, which are more distinctive in the case of powder P1. This indicates the powders to be almost non-crystalline. TEM (transmission electron microscopy) pictures of powder P1 show low amounts of nanocrystals with sizes of about $5 \mathrm{~nm}$ embedded in an amorphous matrix (Figure 3). The nanocrystals were analyzed to be $\mathrm{AlY}_{3}, \mathrm{Li}, \mathrm{Ni}, \mathrm{NiO}$ and $\mathrm{AlYO}_{3}$ by electron diffraction (marked by black arrows in Figure 3b,e). Other phases may be present, but could not unambiguously excluded. The DSC curves (Figure 2b) show exothermic events at $990 \mathrm{~K}$ for powder P1 and at $1000 \mathrm{~K}$ for powder P2, which are attributed to the crystallization of the amorphous fraction of the powder. Compared to amorphous powders with similar compositions $\left(\mathrm{Al}_{86} \mathrm{Ni}_{8} \mathrm{Y}_{6}\right.$ and $\left.\mathrm{Al}_{86} \mathrm{Ni}_{8} \mathrm{La}_{6}\right)$ without $\mathrm{Li}$ the observed crystallization temperatures are strongly increased by $\Delta T \approx 470 \mathrm{~K}$ and $520 \mathrm{~K}$, respectively [13]. This may be caused by the addition of the 4th compound element, which leads to a more complicated phase formation process or the high amount of non-metal elements. In general, Al-based compositions with $\mathrm{Al}$ contents between 85 at.\% and 92 at.\% initiate crystallization in the temperature range of $470 \mathrm{~K} \leq T \leq 520 \mathrm{~K}$ and contain two to three crystallization steps in dependence of the constitution [18-20]. In the binary system Al-Li, present as amorphous material, three exothermic events with low energies are observed which are associated with relaxation processes [21]. These exothermic peaks disappear with increasing milling time indicating a suppressed relaxation due to the highly developed framework of the amorphous material. Up to $990 \mathrm{~K} \mathrm{Al}_{43} \mathrm{Li}_{43} \mathrm{Y}_{6} \mathrm{Ni}_{8}$ no exothermic events typical for relaxation processes, nor an exothermic event assignable to the beginning of a phase 
formation process as observed for Li-free Al-based amorphous alloys are detected [18-20]. However, at $990 \mathrm{~K}$ a phase formation process is induced in contrast to the Al-Li system where no phase formation occurs until melting [21]. Figure 2c supports the absence of crystalline phases at temperatures below $990 \mathrm{~K}$. The presence of $\mathrm{O}$ and $\mathrm{N}$ does not worsen the amorphization process as observed especially for powder P2. Si and Fe are frequently used alloying constituents in bulk metallic glasses, which demonstrate their compatibility as ingredients of amorphous alloys [22,23].

XPS investigations were performed in order to analyze the binding states of the compound elements (Figures 4 and 5). It was observed that the surface layer of the powder mostly consists of Li- and C-compounds. Al, Y, Ni and Fe in oxidic or metallic states are hardly present (Table 2) at the surface. As a consequence, subsequent sputtering was performed in order to eliminate this surface layer. Although sputtering obtained the appearance of the other alloy elements, the achieved depth of about $100 \mathrm{~nm}$ is still within a surface-near area since the atom concentration after sputtering deviates from the chemical analysis (Table 1). A further point to be noted is the impossibility to detect the N, because the relevant $\mathrm{BE}$ area is overlapped by the $\mathrm{BE}$ of $\mathrm{Y}$ which may lead overestimation of the $\mathrm{Y}$ amount in case of high nitrogen concentration. The critical point of XPS analysis of material with low electrical conductivity, as our partly oxidized powders, is the occurrence of peak shifts due to surface charging and the demand for correcting the binding energy (BE) scale. In general, mostly $\mathrm{C}$ from the adventitious carbon contamination is chosen as reference element at a binding energy of around 284.5 to $285.0 \mathrm{eV}$. Though, if the herein presented results would be referenced to this value, all of the metallic elements would be present in their metallic states, which is not possible due to the significant amount of $\mathrm{O}$. Furthermore, the Fe line would be situated at much lower BE than any known position [24]. That requires the consideration which state is the most expected. Due to their high O-affinity Al and Y are estimated to be present as oxides. $\mathrm{Y}$ is not suited as reference since the binding state shows a doublet and the BEs of elemental and oxide lines of this doublet are closely spaced. Assuming Al to be present in its oxide state is assisted by the peak position of $\mathrm{O}$ in the sputtered state, which is related to $\mathrm{Al}_{2} \mathrm{O}_{3}$ (Figures $4 \mathrm{f}$ and 5f). Obviously, at the surface (as-milled state) other oxides, maybe $\mathrm{Li}_{2} \mathrm{O}$, are present. Taking the spectra of all observed elements into account, it was decided to reference the measurements to $\mathrm{Al}_{2} \mathrm{O}_{3}$ at a BE of $74.0 \mathrm{eV}$ (Figures $4 \mathrm{~b}$ and $5 \mathrm{~b}$ ). This referencing is also supported by the fact that only in this case the valence band cut-off in the samples is at $0 \mathrm{eV}$. From this point a BE-shift for $\mathrm{C} 1 \mathrm{~s}$ to $287.0 \mathrm{eV}$ occurs (Figures $4 \mathrm{a}$ and 5a), which has not been discussed in the literature. Nevertheless, other Li-including systems are also found to show similar BE shifts of the $C$ contamination [25]. Otherwise this is still under discussion, nevertheless, already Hoenigman pointed out such a reference level problem between his in situ deposited Li films with respect to C-reference sputter-cleaned material [26]. The evaluation of $\mathrm{Li}$ is also critical due to the close $\mathrm{BE}$ positions of the elemental and oxide lines (Figures $4 \mathrm{c}$ and $5 \mathrm{c}$ ). Powder P2 is assumed to contain Li mainly in its oxide state, both in the as-milled and in the sputtered state. In the case of powder, P1 the Li 1s binding energy peak of the as-milled state is very broad. The sputtered state also shows another difficulty by the overlap of the Fe $3 p$ line with the Li 1s position. Both circumstances disallow further conclusions. Besides the noted difficulties concerning the closely spaced doublet lines the evaluation of the $\mathrm{Y}$ is ambiguous since their BEs are located at around $1 \mathrm{eV}$ higher energy levels (Figures $4 \mathrm{~d}$ and $5 \mathrm{~d}$ ) than in $\mathrm{Y}_{2} \mathrm{O}_{3}$, however, this shift definitely points to $\mathrm{Y}$ in oxide form [24]. The presence of Ni-oxides can be excluded since the characteristic losses, which should then occur at $862 \mathrm{eV}$ are missing [24]. In the case of Fe the 
detection of Fe-oxides is more complicated, since characteristic energy losses are weakly pronounced and therewith are not clearly detectable.

However, the referencing of such a multicomponent system is nontrivial. Moreover, in a complex amorphous system as presented, the bonding relation of $\mathrm{O}$ is hard to compare to crystalline oxides, which we had to use as basis for discussion of the observed BEs. For this reason conclusions have to be drawn critically. It is curious that no metallic BE lines are visible for $\mathrm{Al}, \mathrm{Li}$ and $\mathrm{Y}$, because the amount of $\mathrm{O}$ (Table 2) is insufficient for a complete oxidation of those elements. Building their first or solely oxidation states $\mathrm{Al}_{2} \mathrm{O}_{3}, \mathrm{Li}_{2} \mathrm{O}, \mathrm{Y}_{2} \mathrm{O}_{3}$, $(\mathrm{FeO}$ and $\mathrm{NiO}$ ), respectively, would require an O-content of about 50 at.\% taking into account that $\mathrm{Ni}$ and $\mathrm{Fe}$ are partially metallic which may balance the $\mathrm{O}$-demand of Y. Al and Li exist in equal parts meaning that each metallic atom requires one O-atom. As further signs for the existence of metallic parts, the broadening of the Li-peak (powder P1) has to be noticed. In addition, the TEM investigation indicates a certain amount of metallic phases $\left(\mathrm{Al}_{3} \mathrm{Y}, \mathrm{Li}\right.$, $\mathrm{Ni}$ ) as verified by electron diffraction. Nevertheless, we suppose the mentioned stable oxide-like peak position as a specific property of our amorphous compound and the oxygen deficiency as hint for metallic-like parts, especially when keeping in mind that the real bulk has not yet reached by sputtering of the $\mu \mathrm{m}$-shaped particles.

Table 2. Atomic concentration table of the XPS measurement.

\begin{tabular}{ccccc}
\hline \multirow{2}{*}{ Electron shell } & \multicolumn{2}{c}{ Powder P1 (steel vial) } & \multicolumn{2}{c}{$\begin{array}{c}\text { Powder P2 } \\
\text { (silicon nitride vial) }\end{array}$} \\
\cline { 2 - 5 } & As-milled & Sputtered & As-milled & Sputtered \\
\cline { 2 - 5 } & Amount [at.\%] & Amount [at.\%] & Amount [at.\%] & Amount [at.\%] \\
\hline Li 1s & 39.99 & 50.22 & 37.49 & 23.67 \\
$\mathrm{C} 1 \mathrm{~s}$ & 8.81 & 0.00 & 8.29 & 0.66 \\
$\mathrm{O} 1 \mathrm{~s}$ & 47.13 & 23.80 & 48.06 & 39.33 \\
$\mathrm{Al} 2 \mathrm{p}$ & 3.30 & 18.71 & 5.28 & 29.04 \\
$\mathrm{Fe} 2 \mathrm{p}_{3 / 2}$ & 0.24 & 2.64 & - & - \\
$\mathrm{Ni} 2 \mathrm{p}$ & 0.06 & 1.02 & 0.13 & 1.69 \\
$\mathrm{Y} \mathrm{3d}$ & 0.46 & 3.16 & 0.74 & 5.60 \\
\hline
\end{tabular}

In order to clarify the oxidation state of Fe more precisely as it was possible by XPS, transmission Mössbauer spectroscopy was performed (Figure 6 and Table 3). The Mössbauer spectrum consists of a sextet, a paramagnetic doublet and a strong background symmetrically to the zero velocity. Because of its hyperfine parameters, the sextet can definitely be attributed to metallic $\alpha$-Fe. The doublet has to be ascribed to bonded $\mathrm{Fe}^{3+}$. This $\mathrm{Fe}$ may be either oxidized or bonded to another matrix element. The third subspectrum, the strong background, may originate from superparamagnetic Fe, i.e., Fe in small nanometer-sized clusters with varying diameter and/or composition. The statistics of the measurement and the broadening of the related peak, however, does not allow to distinguish further between these sites. Moreover, it was found that the majority of ${ }^{57} \mathrm{Fe}$ atoms do not give a coherent signal, i.e., they are located at sites with largely varying local geometry. This corroborates the assumption of a relatively homogeneous intermixture of the components, as sketched in Figure 1. 
Table 3. Mössbauer data for powder P1.

\begin{tabular}{|c|c|c|c|c|c|}
\hline Line & $\begin{array}{c}\text { Isomer shift } \\
\text { relative to } \alpha-F e\end{array}$ & $\begin{array}{c}\text { Magnetic } \\
\text { hyperfine field } \\
(\alpha-F e: \text { 33T })\end{array}$ & $\begin{array}{l}\text { Quadrupole } \\
\text { splitting }\end{array}$ & $\begin{array}{c}\text { Areal } \\
\text { fraction }\end{array}$ & Interpretation \\
\hline Sextet & $0.03 \mathrm{~mm} / \mathrm{s}$ & $32.6 \mathrm{~T}$ & - & $33 \%$ & ferromagnetic $\alpha$-Fe \\
\hline Doublet & $0.32 \mathrm{~mm} / \mathrm{s}$ & $0 \mathrm{~T}$ & $0.98 \mathrm{~mm} / \mathrm{s}$ & $10 \%$ & $\mathrm{Fe}^{3+}$ \\
\hline Singulet & $0.08 \mathrm{~mm} / \mathrm{s}$ & $0 \mathrm{~T}$ & - & $57 \%$ & $\begin{array}{c}\text { Superparamagnetic } \\
\text { metallic Fe }\end{array}$ \\
\hline
\end{tabular}

Figure 2. (a) XRD patterns of ball milled $\mathrm{Al}_{43} \mathrm{Li}_{43} \mathrm{Ni}_{8} \mathrm{Y}_{6}$ powders: $\mathrm{P} 1$ (steel milling vial) and P2 (silicon nitride milling vial) before and after cycling; (b) DSC curves of the powders $\mathrm{P} 1$ and $\mathrm{P} 2$ (heating rate $20 \mathrm{~K} / \mathrm{min}$ ); (c) XRD patterns of powder P2, annealed by DSC. Annealing at $1273 \mathrm{~K}$ is carried out within a furnace in a sealed Ta-crucible, because the melting temperature of the mandatory silver foil limits the applicability of DSC.

a)

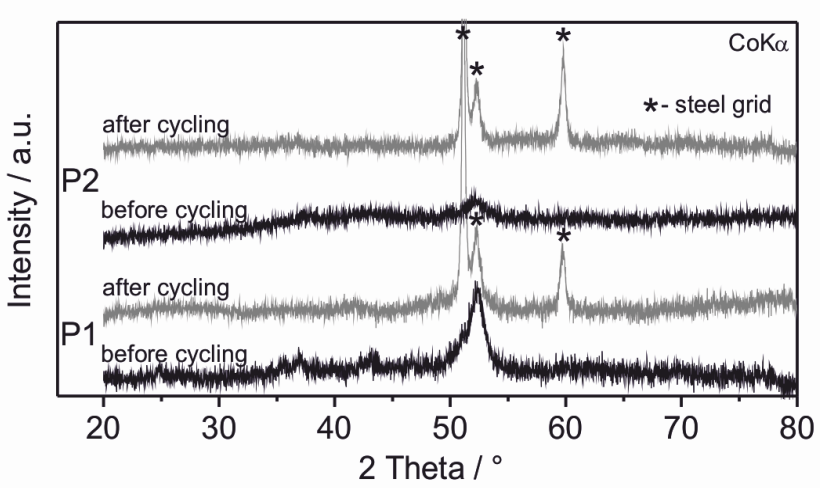

b)

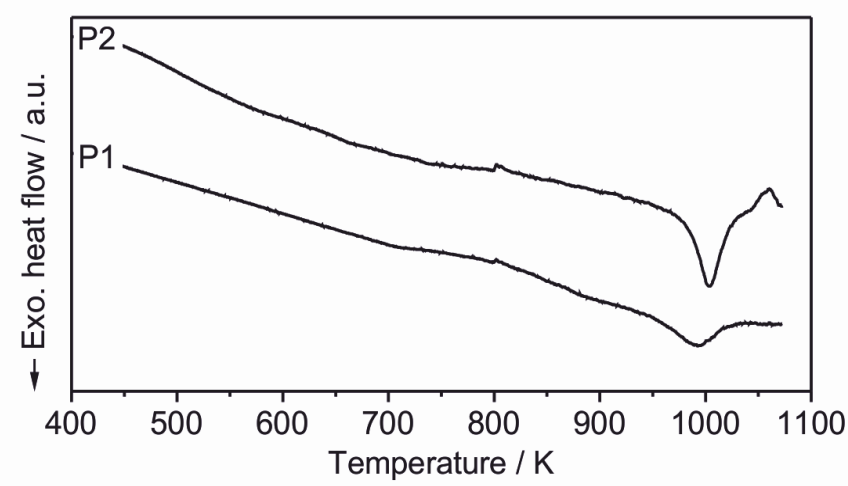

c)

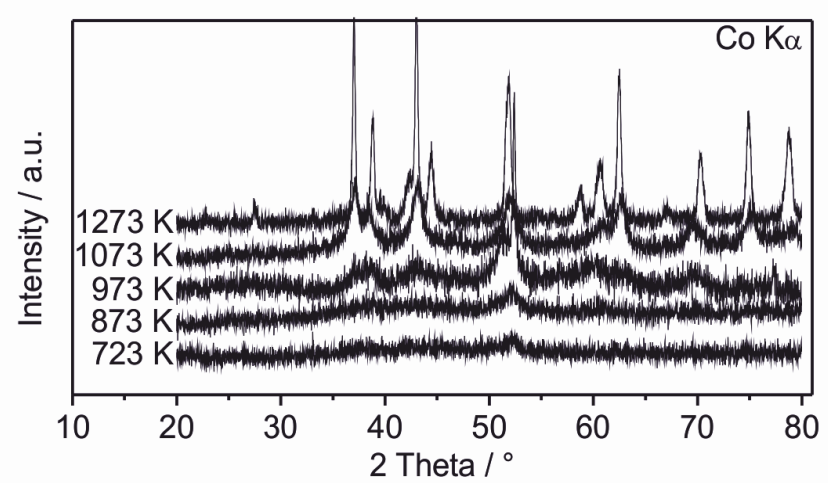


Figure 3. TEM investigation of powder P1 (a-c: as-milled; d-f: after galvanostatic cycling): (a,d) Brightfield images showing typical powder particles (inserted: diffraction patterns); (b,e) Darkfield images: The bright spots indicate nanocrystals, some of them are marked by arrows); (c,f) High resolution micrographs showing some of the nanocrystals indicated by visible lattice fringes (highlighted by black lines).
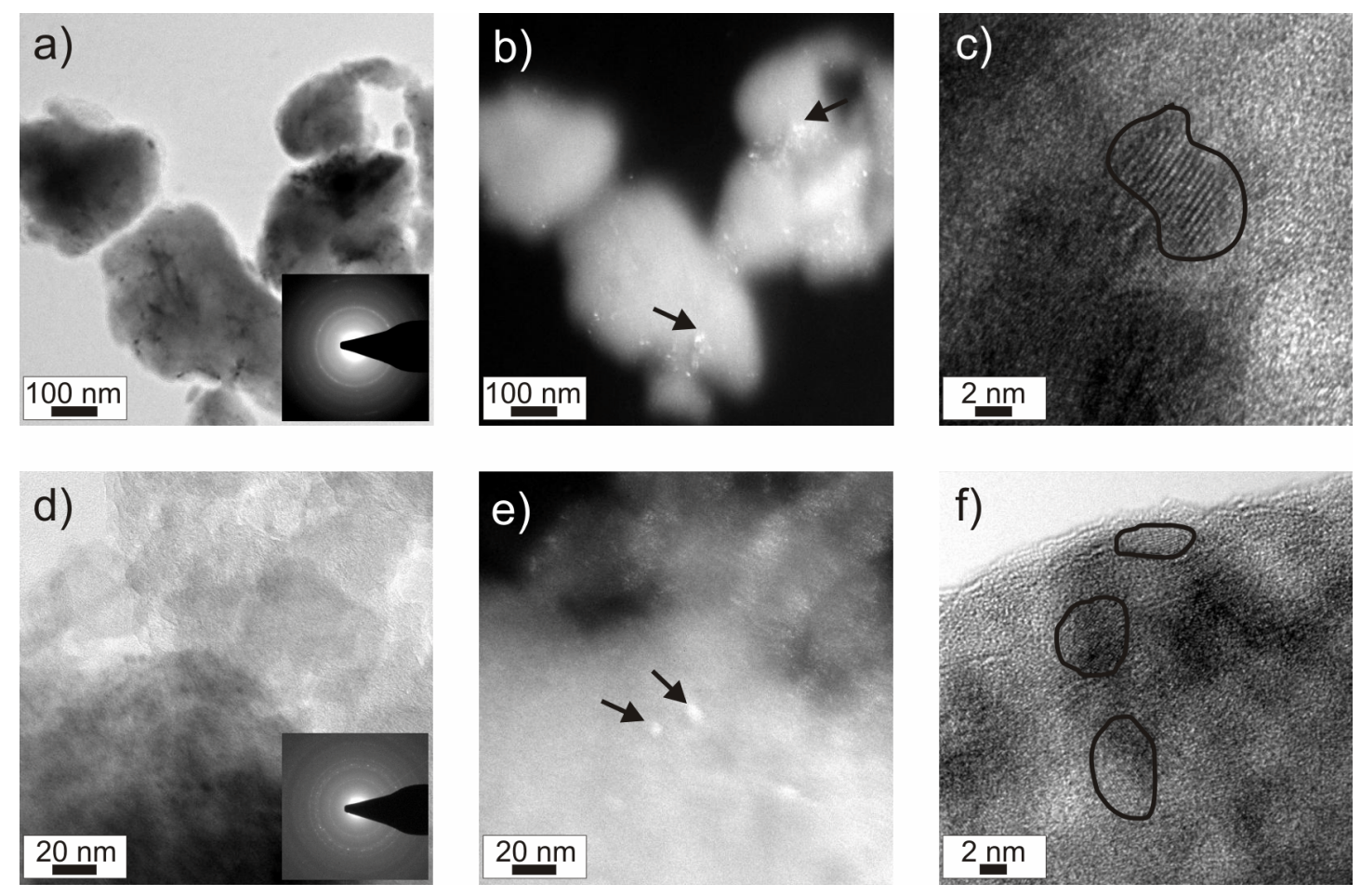

Figure 4. XPS diagrams of powder P1 including the binding energy lines of the elements $\mathrm{C}$ (a), Al (b), Li (C), Y (d), Ni (e), O (f) and Fe (g). The grey areas mark the theoretic energy ranges as referenced by Moulder et al. [24]. The right, light grey areas indicate the position of the elemental line; left positioned, dark grey areas indicate oxide states.

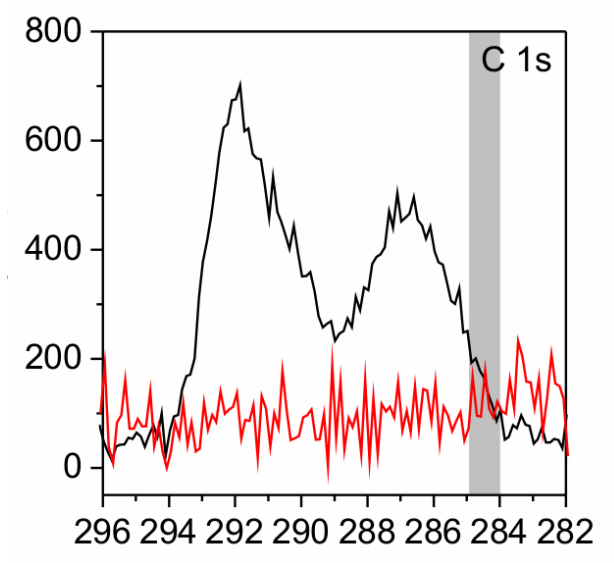

Binding energy / eV

(a)

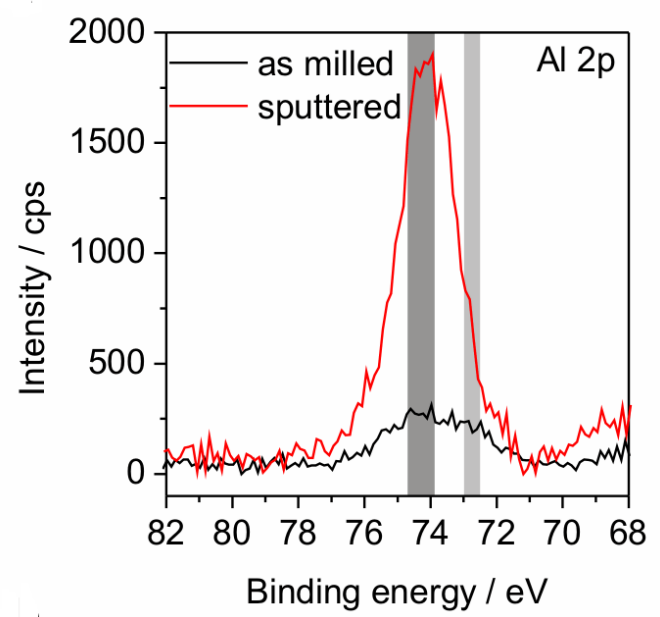

(b) 
Figure 4. Cont.

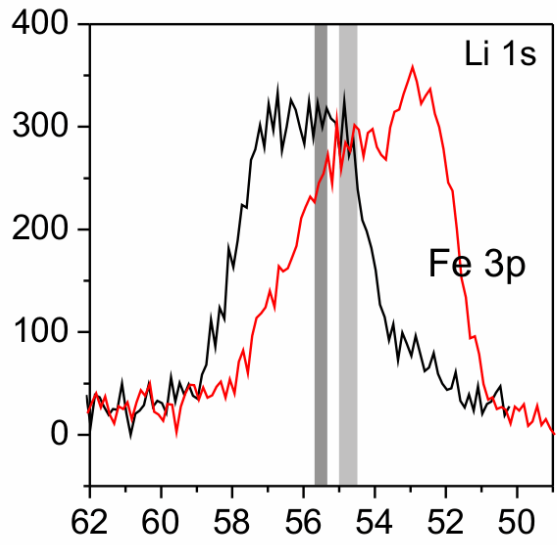

Binding energy / eV

(c)

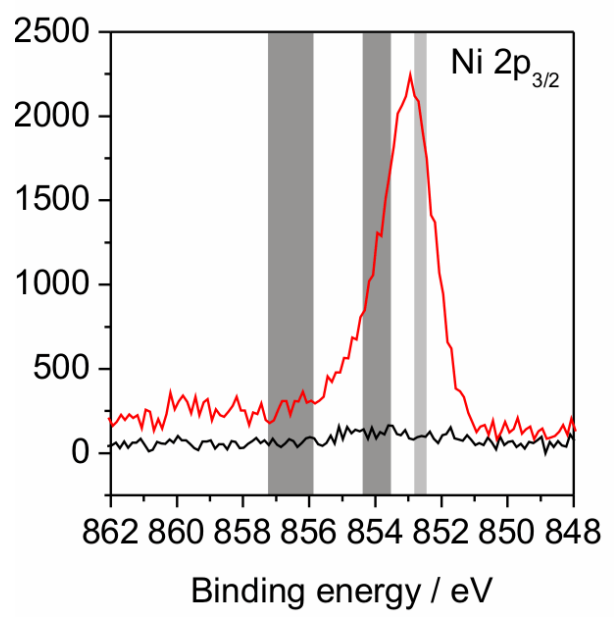

(e)

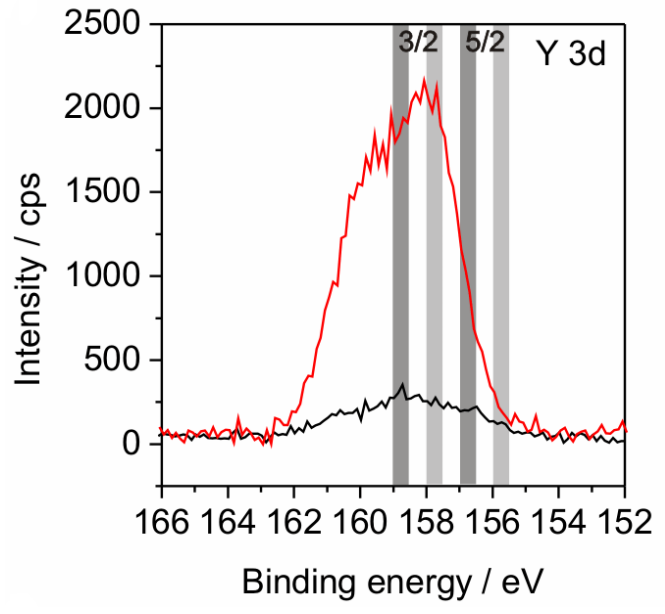

(d)

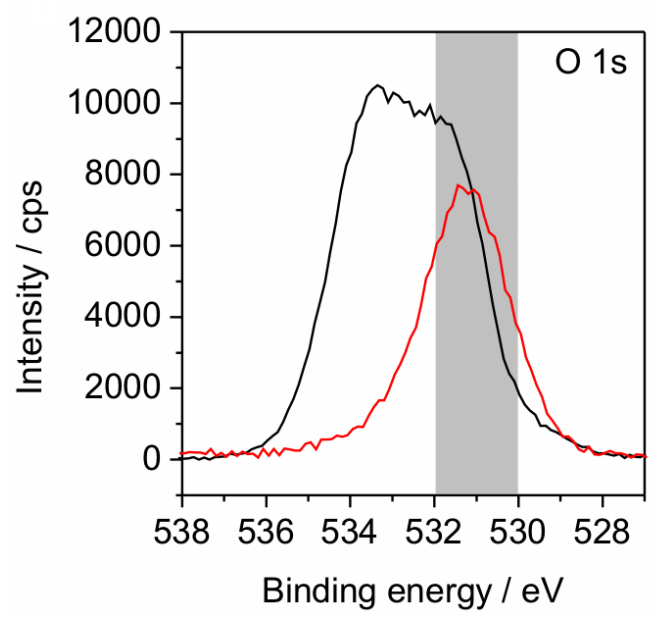

(f)

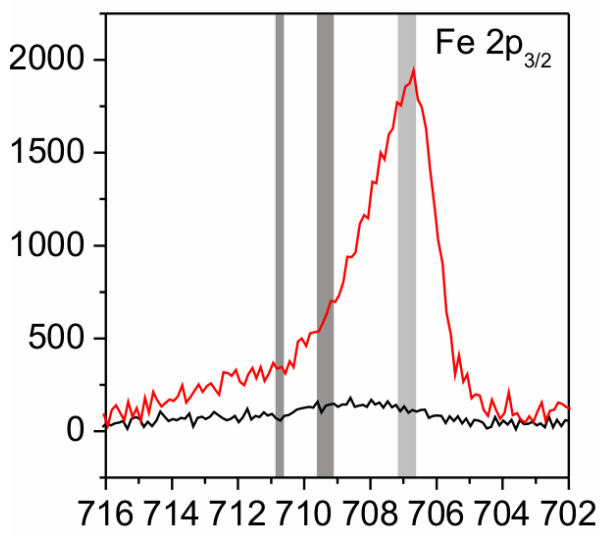

Binding energy / eV

(g) 
Figure 5. XPS diagrams of powder $\mathrm{P} 2$ including the binding energy lines of the elements $\mathrm{C}$ (a); $\mathrm{Al}$ (b); Li (c); Y (d); Ni (e) and O (f). The grey areas mark the theoretic energy ranges as referenced by Moulder et al. [24]. The right, light grey areas indicate the position of the elemental line; left positioned, dark grey areas indicate oxide states.

a)

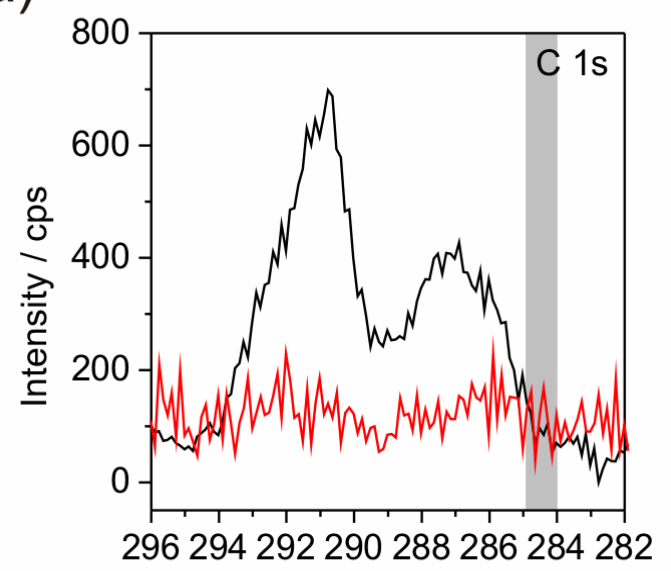

c)

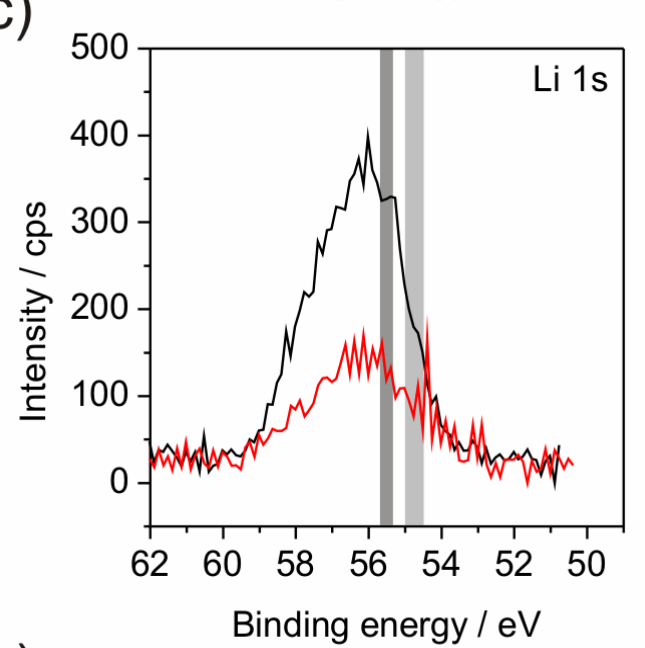

e)

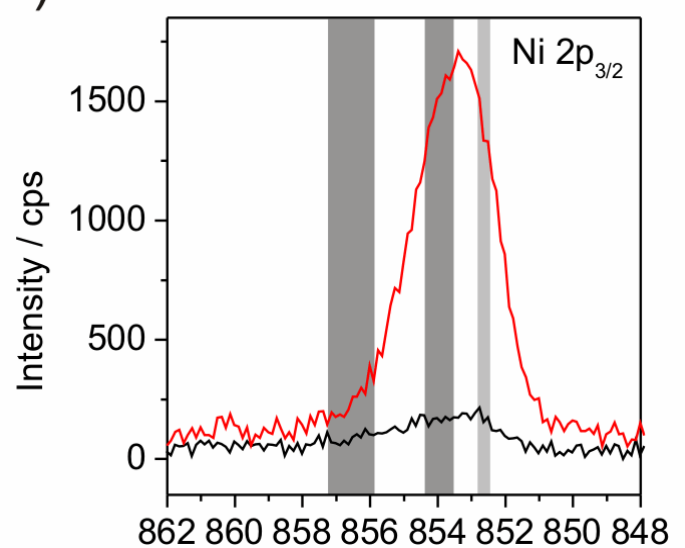

Binding energy / eV b)

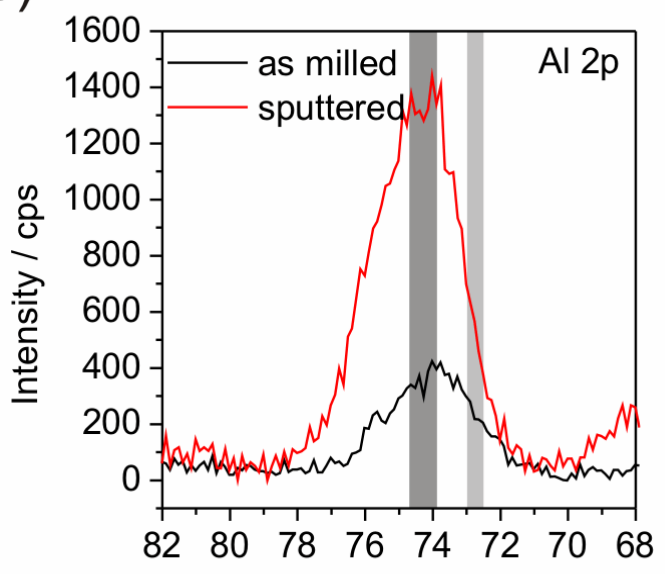

d)

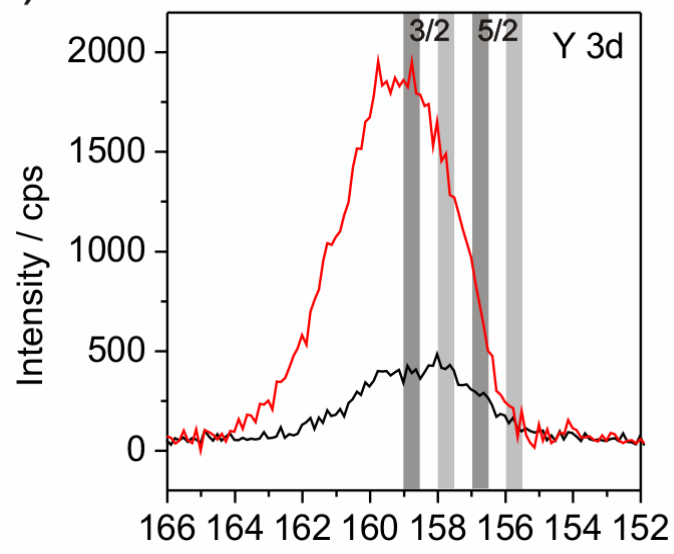

Binding energy / eV

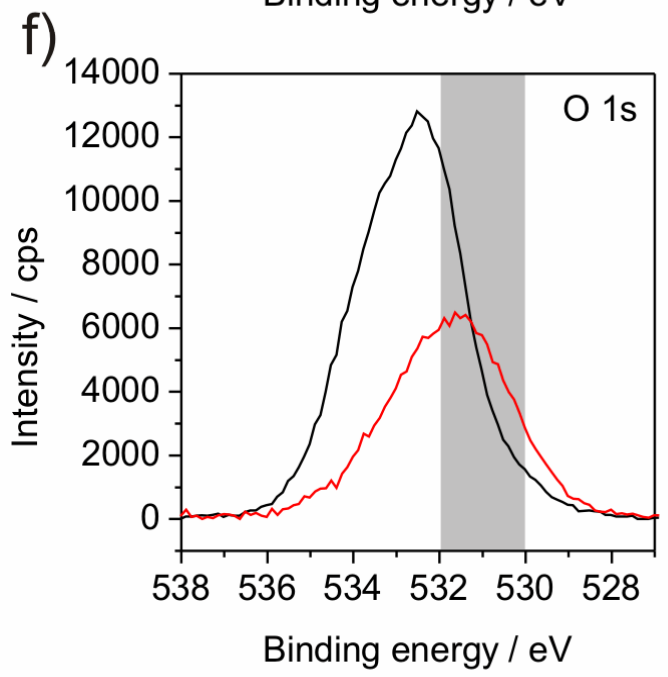


Figure 6. Mössbauer spectra and fitting subspectra for powder P1.

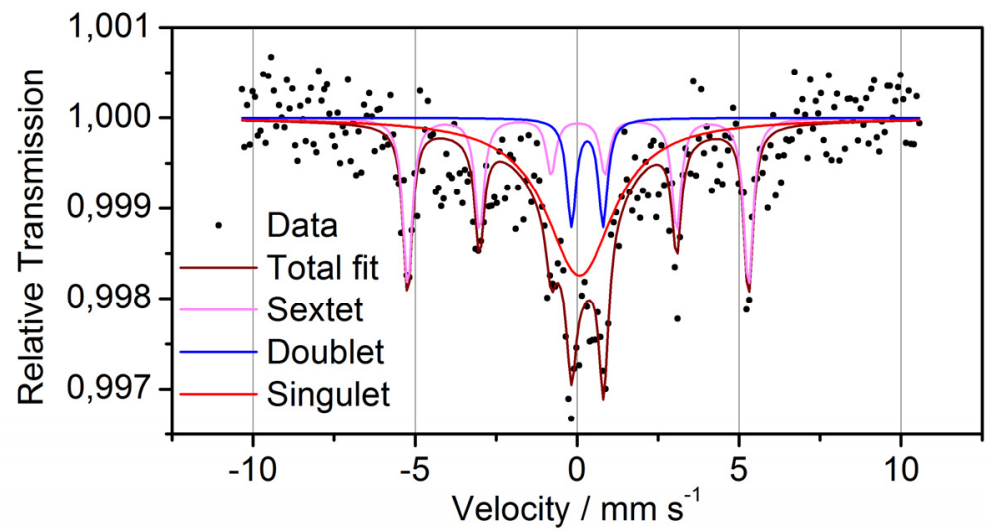

\subsection{Electrochemical Characterization}

Electrodes of the two powders were galvanostatically cycled. The lithiation process occurs mainly between $1.5 \mathrm{~V}$ and the low voltage limit of $0.1 \mathrm{~V}$ (Figure $7 \mathrm{a}, \mathrm{b}$ ). No plateau at a certain potential is observed indicating that no crystalline phase is formed upon lithiation. In contrast, the potential upon delithiation ranges between $0.1 \mathrm{~V}$ and the upper potential limit of $4.0 \mathrm{~V}$. Around $60 \%$ of the delithiation is passed until the potential reaches $2.5 \mathrm{~V}$. Between $2.5 \mathrm{~V}$ and $3.8 \mathrm{~V}$ the slope of the curve is enhanced, which may be caused by the formation of Li-compounds hindering a further Li-diffusion. Fixing this potential range to a lower or upper limit results in a loss of specific capacity (Figure 7c,d). As a conclusion, the electrode is electrochemically active in a wide potential range. This limits on the one hand the specific capacity while choosing a certain smaller potential range, but on the other hand qualifies the material as versatilely applicable electrode. This behavior may originate from the high amount of non-metallic elements. For this experiment, the cycles are started with the delithiation process (Figure 7a,b). During the following lithiation process, a significantly higher amount of Li can be inserted than extracted before. Furthermore, it is also possible, to start the cycling process with the lithiation process. Hence, the amorphous material includes already a certain free volume or a diffusion process of Li through the amorphous framework occurs without fracturing. Figure 8a,b show the development of the specific capacities after each cycle for different C-rates calculated to the amount of Al. As expected, the specific capacity reaches different values as a function of the C-rates. The slower the battery is charged, the higher is the specific capacity. Generally, this rule applies to the performed electrochemical tests. The first cycle shows an irreversible charge capacity loss, which is associated with SEI (solid electrolyte interface) formation [1]. This behavior appears only for the measurements with $\mathrm{C}$-rates of $\mathrm{C} / 10$ and lower. The measurements with $\mathrm{C}$-rates of $\mathrm{C} / 20$ and $\mathrm{C} / 50$, respectively, show a capacity enhancement after the first cycle, which is followed by a capacity loss after the second cycle. As origin an activation process of the surface or the overcoming of a kinetic limitation, which only appears in case of slow lithiation, is possible. Comparing the electrochemical results of P1 and P2 both powders shows very small differences in the specific capacities of the measurements with the C-rates of C/20 and C/10. Generally, the capacities of powder P1 are higher than those of P2. Powder P1 differs from P2 by containing a certain amount of Fe. While no Li-compounds are known for Fe, Ni and Y, Fe oxides are able to form Li-containing compounds [27-29]. However, the presence of Fe or 
Fe-oxides influences the lithiation process positively, since powder P1 achieves enlarged specific capacities compared to P2. Similar promoting effects of Fe or Fe compounds are well documented in disciplines beside battery or electrochemical research such as heterogeneous catalysis [30,31]. Figures $8 \mathrm{c}, \mathrm{d}$ show the development of the specific capacities after each cycle at a C-rate of $\mathrm{C} / 50$ calculated for different active masses. Within an amorphous framework contributing components are hardly relatable to a certain electrochemical activity due to the absence of crystalline phases upon the lithiation process. In principle, $\mathrm{Ni}$ and $\mathrm{Y}$ are electrochemically inactive. Due to their function as glassformers they may be considered as a kind of active, because the amorphous state would otherwise not exist. As a result, the mass of all participating components should be considered giving a practical value for the specific capacity.

Furthermore, the powders P1 and P2 were subjected to long-term measurements in order to estimate their cycle life-time. Figure 9a shows the development of the specific capacities over 100 cycles at a rate of $\mathrm{C} / 20$. The capacity of powder $\mathrm{P} 2$ continuously decreases after the second cycle, starting at a value of $420 \mathrm{Ah} \mathrm{kg}^{-1}$. In contrast, the capacity of powder P1 starts at a value of $550 \mathrm{Ah} \mathrm{kg}^{-1}$ and decreases discontinuously, reaching a plateau between the 4th and 14th cycle. After the 22nd cycle the capacity continuously decreases as observed for powder P2. The lithiation and delithiation processes occur quasi-continuously between the lower potential limit of $0.1 \mathrm{~V}$ and $2.5 \mathrm{~V}$ in the case of lithiation and between $1.5 \mathrm{~V}$ and $0.1 \mathrm{~V}$ in the case of delithiation, as no plateau is observed at a certain potential (Figure 9b). Therewith, no new crystalline phases are formed. Both powders remain in an amorphous state as evidenced by XRD (Figure 1a). While galvanostatic cycling Li is reversibly inserted and removed into or out of the material without a significant capacity loss after the first cycles (Figure 3a,b). Compared to crystalline $\mathrm{Al}$ (dashed line in graphs) amorphous Li-compounds offer stable electrochemical properties for the application in Li-ion batteries (Figure 1a,b). After 100 cycles the herein investigated materials still achieve specific capacities of $150 \mathrm{Ah} \mathrm{kg}^{-1}$ in the case of powder $\mathrm{P} 2$ and $220 \mathrm{Ah} \mathrm{kg}^{-1}$ for powder P1. Indeed, those coulomb efficiencies of $35 \%$ and $40 \%$, respectively, do not give a glamorous electrochemical long term performance. However, the constant curve voltage profile demonstrates in principle the ongoing of unchanged electrochemical processes during the cycling procedure (Figure 9b). The quicker Li-insertion processes can be caused by pinning of Li within the material or by plating at the surface, thus leading to a loss of specific capacity [32]. Further investigations should help to optimize the capacity during long term cycling.

In general, crystalline intermetallic phases achieve increased specific capacities compared to the well-known properties of graphite. Disadvantageously, the decomposition after a few cycles caused by huge volume changes during lithiation turn them unsuitable for a battery application [2]. This circumstance is avoided by the application of amorphous compounds. Conventional amorphous alloys do not provide sufficient free volume for Li-migration [13]. The novelty of the herein presented amorphous compound $\mathrm{Al}_{43} \mathrm{Li}_{43} \mathrm{Y}_{6} \mathrm{Ni}_{8}$ is the combination of the advantages of electronegative elements and their high specific capacities, here Al, with the stiffness of an amorphous framework which cannot undergo phase transitions, but provides Li-migration paths by integrating Li into the master alloy. This new lithiation mechanism is introduced in contrast to the phase transition mechanism of crystalline intermetallics and furthermore the intercalation mechanism of $\mathrm{Li}$ into layered structures like graphite. The mechanism may be promoted by the non-metallic elements and Fe-oxides at the particle surfaces allowing faster migration at the grain boundaries. 
Figure 7. Lithiation process of ball milled amorphous $\mathrm{Al}_{43} \mathrm{Li}_{43} \mathrm{Ni}_{8} \mathrm{Y}_{6}$ powders $\mathrm{P} 1$ (a) and P2 (b) versus potential. Development of specific capacities in dependency of different potential ranges for P1 (c) and P2 (d).

a)

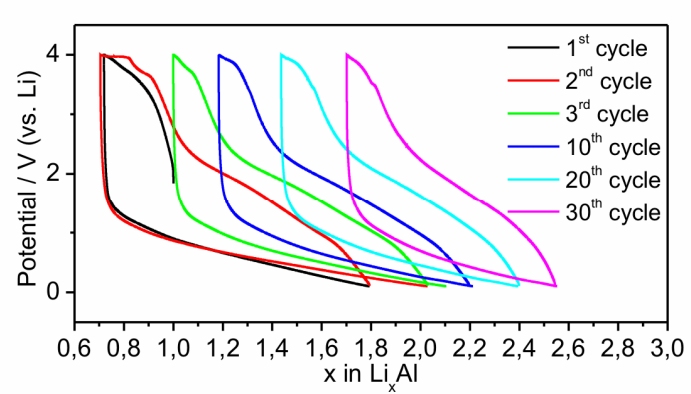

c)

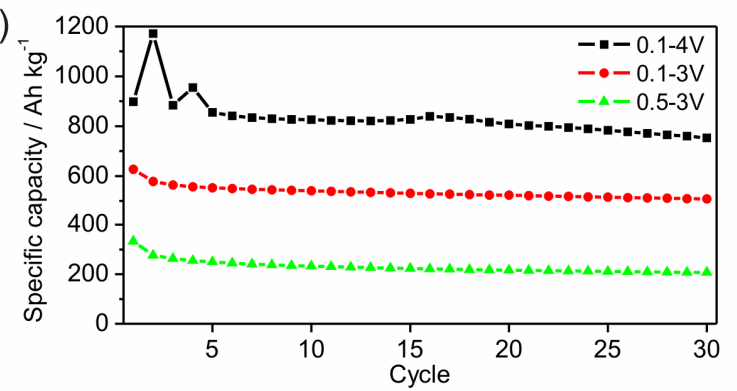

b)

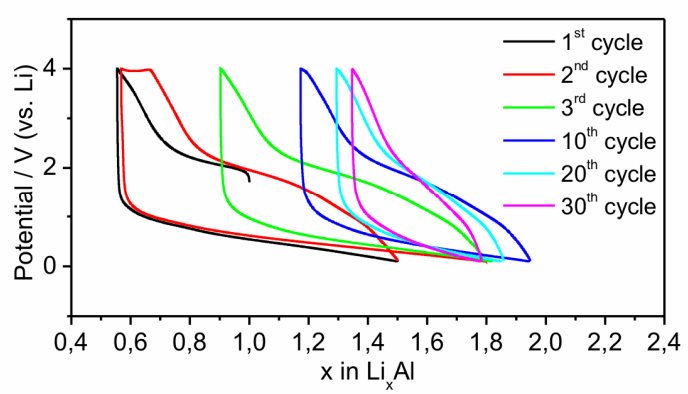

d)

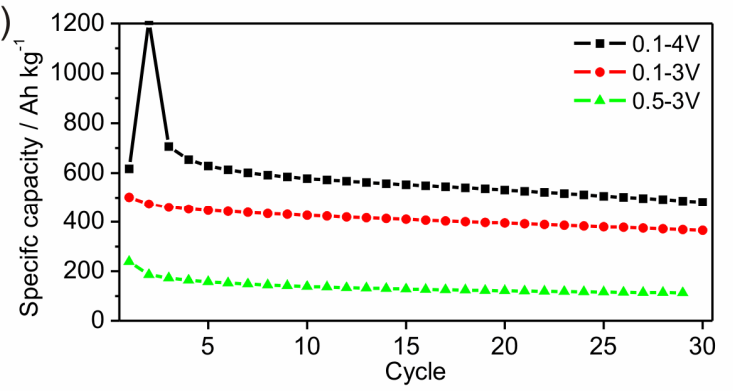

Figure 8. Development of specific capacities of ball milled amorphous $\mathrm{Al}_{43} \mathrm{Li}_{43} \mathrm{Ni}_{8} \mathrm{Y}_{6}$ powders $\mathrm{P} 1$ (a) and $\mathrm{P} 2$ (b), galvanostatically cycled between $0.1 \mathrm{~V}$ and $4 \mathrm{~V}$ with $\mathrm{C}$-rates of $\mathrm{C} / 50, \mathrm{C} / 20, \mathrm{C} / 10, \mathrm{C} / 5$ and $\mathrm{C}$, respectively. The dashed lines give the development of the specific capacity of crystalline Al-powder taken as reference with a particle size of $18 \mu \mathrm{m}$, cycled between $0.1 \mathrm{~V}$ and $2 \mathrm{~V}$ with a rate of $\mathrm{C} / 50$. Specific capacities at the C-rate of $\mathrm{C} / 50$ calculated for different active masses for P1 (c) and P2 (d).

a)

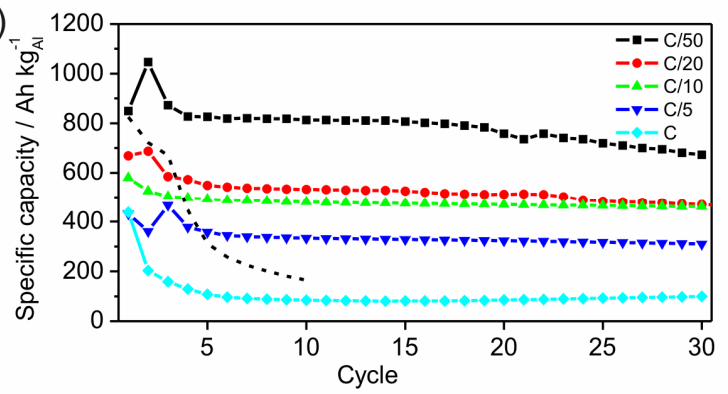

c)

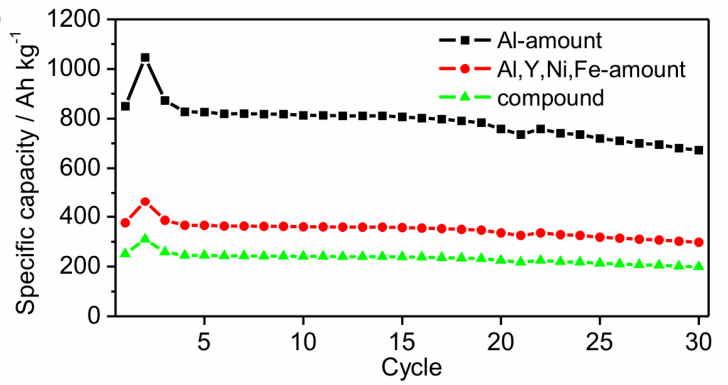

b)

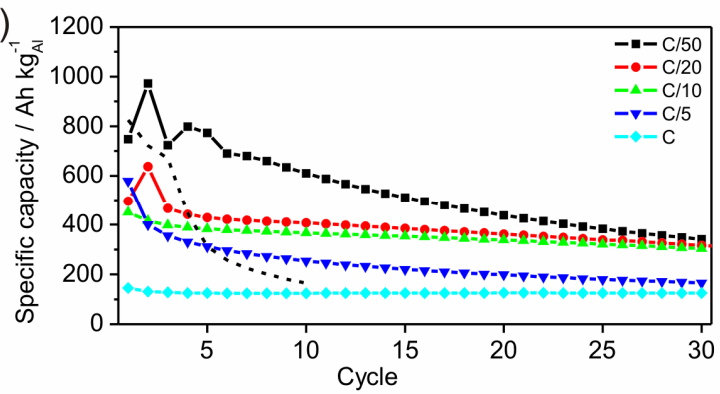

d)

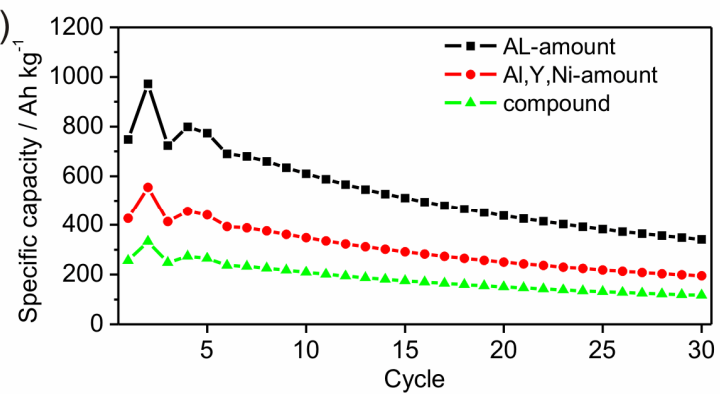


Figure 9. Development of specific capacities of amorphous $\mathrm{Al}_{43} \mathrm{Li}_{43} \mathrm{Ni}_{8} \mathrm{Y}_{6}$ powders $\mathrm{P} 1$ and $\mathrm{P} 2$, galvanostatically cycled between $0.1 \mathrm{~V}$ and $4 \mathrm{~V}$ with a rate of $\mathrm{C} / 20$ over 100 cycles (a); Voltage profile of powder P1 (b).

a)

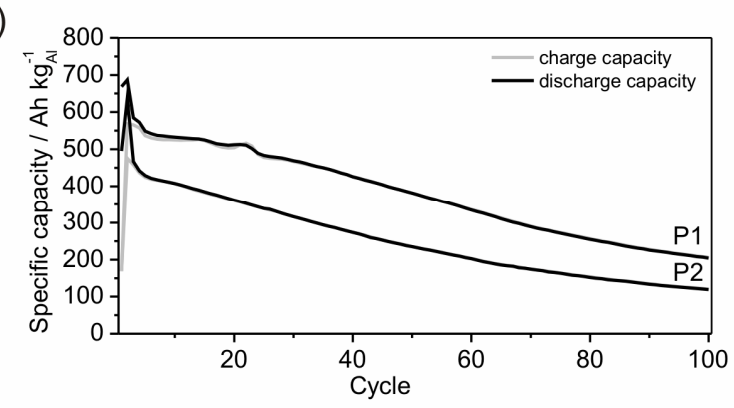

b)

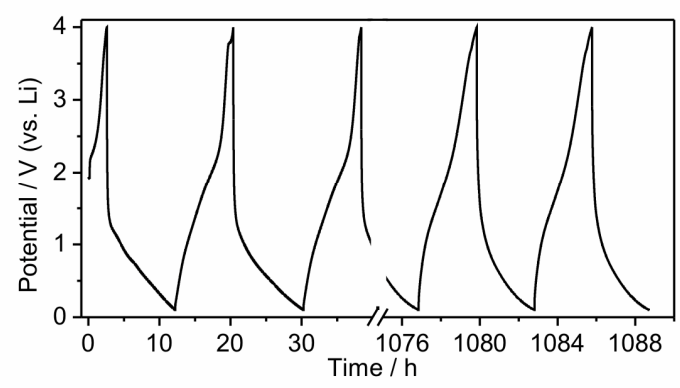

\section{Experimental Section}

A master alloy with nominal composition $\mathrm{Al}_{43} \mathrm{Li}_{43} \mathrm{Y}_{6} \mathrm{Ni}_{8}$ (at.\%) was prepared by melting the pure elements Al (Alfa Aesar, 99.999\%, Karlsruhe, Germany), Li (Alfa Aesar, 99.9\%, Karlsruhe, Germany), Ni (Chempur, 99.98\%, Karlsruhe, Germany) and Y (Chempur, 99.9\%, Karlsruhe, Germany) within sealed Ta-tubes under Ar-atmosphere in an induction furnace (Hüttinger). Ni and Y serve as glass formers and are added to achieve amorphization. High energy ball milling (Pulverisette 7 premium line, Fritsch) was applied in order to pulverize the ingots and additionally to transfer the powder to an amorphous state (for details about amorphization through solid state reaction /high energy ball milling, see [33]). The milling time was $48.5 \mathrm{~h}$, consisting of $10 \mathrm{~min}$. milling cycles at $450 \mathrm{rpm}$ and $20 \mathrm{~min}$. breaks. Two vials with pressure-relief valves were used. Powder P1 was milled in a steel vial leading to an input of wear debris arising from the vial. Powder P2 was milled in a silicon nitride vial. Here, no significant wear debris could be detected (Table 1). The powder composition was chemically analyzed by inductively coupled plasma-optical emission spectrometry (ICP-OES, IRIS Intrepid II, Thermo Scientific) after dissolving in hydrochloric acid at $696 \mathrm{~K}$ with respect to metallic components and by the carrier gas hot extraction methods with respect to oxygen and nitrogen concentration (TC436DR, Leco). The results of the chemical analyses are compiled in Table 1. The amorphous state of the milled powder was verified by X-ray powder diffraction (XRD) using a Panalytical Xpert Pro diffractometer with Co $\mathrm{K} \alpha$ radiation and a Pixel detector in Bragg-Brentano geometry. High temperature differential scanning calorimetry (Netzsch DSC 404) was performed employing a heating rate of $20 \mathrm{~K} \mathrm{~min}^{-1}$. Due to its high vapor pressure, the powder was packed in silver foil within the aluminum oxide DSC crucible. The powder morphology and structure were investigated by transmission electron microscopy (TEM) using a Tecnai F30 (FEI) microscope. TEM sample preparation was realized by dripping a dilute DMC-suspension onto a carbon-coated Cu-grid. X-ray photoelectron spectroscopy (PHI 5600, Physical Electronics) was applied on the as-milled powder and after sputtering in a depth of approximately $100 \mathrm{~nm}$ in order to identify the oxidation state of the elements, especially of Fe (wear debris) for the powder P1. The investigation was performed with an $\mathrm{Al} \mathrm{K \alpha 1}$ beam $(350 \mathrm{~W})$ and a hemispherical analyzer operated at a pass energy of $29 \mathrm{eV}$. Sputtering was realized by $\mathrm{Ar}^{+}$ions using a beam energy of $3.5 \mathrm{keV}$ with an approximated sputtering rate of $5 \mathrm{~nm} \mathrm{~min}{ }^{-1}$. The Mössbauer spectra were obtained at the isotope ${ }^{57} \mathrm{Fe}$ within the absence of air at room temperature. Therefore a WissEl 
(Wissenschaftliche Elektronik GmbH, Starnberg, Germany) electromechanical spectrometer working in a constant acceleration mode with a ${ }^{57}$ Co source was applied. The spectra were processed using the NORMOS program package [34].

For electrochemical experiments, the powders were sieved in order to separate a fine particle fraction of $20-45 \mu \mathrm{m}$ diameter. Electrodes were prepared by mixing the achieved powders with carbon (Super PLi, Timcal, Bodio, Switzerland) and polyvinyliden difluoride (SOLEF 1013, Solvey, Brussels, Belgium), as conductive additive and filler (ratio 8:1:1). In order to form the electrodes the mixture was pressed onto steel grids. These electrode grids were dried under Ar-atmosphere at $373 \mathrm{~K}$ for $12 \mathrm{~h}$. Test cells (Swagelok) were assembled in a glove box under $\mathrm{O}_{2}$ - and $\mathrm{H}_{2} \mathrm{O}$-controlled $(<0.1 \mathrm{ppm})$ Ar-atmosphere using the electrolyte LP30 (1 $\mathrm{M} \mathrm{LiPF}_{6}, 1: 1 \mathrm{DMC} / \mathrm{EC}$, Merck, Darmstadt, Germany) and lithium (Chemetall, 99.9\%, Frankfurt am Main, Germany) as counter electrode. The cells were electrochemically tested by galvanostatic cycling for 30 and 100 times, respectively, between 0.1 and $4 \mathrm{~V}$ at current densities between $42 \mathrm{~A} \mathrm{~kg}^{-1}$ and $1570 \mathrm{~A} \mathrm{~kg}^{-1}$ according to C-rates between $\mathrm{C} / 50$ and $1 \mathrm{C}$ in relation to the molar mass of the $\mathrm{Al}$-amount as measured by chemical analysis.

\section{Conclusions}

An advanced amorphous compound with the initial atomic composition $\mathrm{Al}_{43} \mathrm{Li}_{43} \mathrm{Y}_{6} \mathrm{Ni}_{8}$ was prepared by high energy ball milling of a master compound. The novelty of the compound investigated in the present work is the integration of $\mathrm{Li}$ within the initial, uncycled amorphous framework. During charging $\mathrm{Li}$ is electrochemically removed while subsequent discharging restores the lithiated state. Thus, the active amorphous host retains diffusion pathways, which enables a reversible lithiation and avoids large volume changes. $\mathrm{O}, \mathrm{N}$ and $\mathrm{Fe}$ neither hinder the amorphization nor the electrochemical processes. The presence of Fe and Fe-oxides, respectively, even leads to a further improved specific capacity and life time. The present results confirm the approach of amorphous compounds to be promising materials, which can overcome the volume changes leading to the breakage of crystalline compound electrodes. Powder electrodes of this material give a remarkable electrochemical performance by achieving high specific capacities of around $800 \mathrm{Ah} / \mathrm{kg}_{\mathrm{Al}}$ within the first cycles. Hence, this approach opens a new way for designing and tailoring of a new class of amorphous electrode materials for high performance batteries with significantly increased specific capacity compared to graphite and a striking cycling stability compared to crystalline compounds without decomposition upon extended cycling.

\section{Acknowledgments}

The authors are indebted to I. Chumak for technical support and A. Voss, A. Voidel, H. Bußkamp, C. Geringswald, R. Buckan and W. Gruner for carrying out the chemical analyses. F. Thoss gratefully acknowledges the Deutsche Bundesstiftung Umwelt for financial funding. Further financial support is received from the European Union and the Free State of Saxony (SAB grant no. 100112628) within the European Centre for Emerging Materials and Processes Dresden (ECEMP). 


\section{Conflicts of Interest}

The authors declare no conflict of interest.

\section{References}

1. Daniel, C.; Besenhard, J.O. Handbook of Battery Materials, 2nd ed.; Wiley-VCH: Weinheim, Germany, 2011; pp. 70,508.

2. Winter, M.; Besenhard, J.O. Rechargeable batteries. Chem. Unserer. Zeit. 1999, 33, 320-332.

3. Aifantis, K.E.; Hackney, S.A. Mechanical stability for nanostructured Sn- and Si-based anodes. J. Power Sources 2011, 196, 2122-2127.

4. Shen, L.; Zhang, X.; Uchaker, E.; Yuan, C.; Cao, G. $\mathrm{Li}_{4} \mathrm{Ti}_{5} \mathrm{O}_{12}$ Nanoparticles Embedded in a Mesoporous Carbon Matrix as a Superior Anode Material for High Rate Lithium Ion Batteries. Adv. Energy Mater. 2012, 2, 691-698.

5. Phan, V.P.; Pecquenard, B.; Cras, F. High-Performance All-Solid-State Cells Fabricated With Silicon Electrodes. Adv. Funct. Mater. 2012, 22, 2580-2584.

6. Idota, Y.; Kubota, T.; Matsufuji, A.; Maekawa, Y.; Miyasaka, T. Tin-based amorphous oxide: A high-capacity lithium-ion-storage material. Science 1997, 276, 1395-1397.

7. Foster, D.; Wolfenstine, J.; Read, J.; Allen, J.L. Performance of Sony's Alloy Based Li-Ion Battery; ARL-TN-0319; U.S. Army Research Laboratory: Adelphi, MD, USA, 2008; pp. 1-14.

8. Applestone, D.; Yoon, S.; Manthiram, A. $\mathrm{Cu}_{2} \mathrm{Sb}_{-} \mathrm{Al}_{2} \mathrm{O}_{3}-\mathrm{C}$ nanocomposite alloy anodes with exceptional cycle life for lithium ion batteries. J. Mater. Chem. 2012, 22, 3242-3248.

9. Lewis, R.B.; Timmons, A.; Mar, R.E.; Dahn, J.R. In situ AFM measurements of the expansion and contraction of amorphous Sn-Co-C films reacting with lithium. J. Electrochem. Soc. 2007, 154, A213-A216.

10. Al-Maghrabi, M.A.; Thorne, J.S.; Sanderson, R.J.; Byers, J.N.; Dahn, J.R.; Dunlap, R.A. A Combinatorial Study of the Sn-Si-C System for Li-Ion Battery Applications. J. Electrochem. Soc. 2012, 159, A711-A719.

11. Datta, M.; Maranchi, J.; Chung, S.J.; Epurc, R.; Kadakiad, K. Amorphous silicon-carbon based nano-scale thin film anode materials for lithium ion batteries. Electrochim. Acta 2011, 56, 4717-4723.

12. Murugesan, S.; Harris, J.T.; Korgel, B.A.; Stevenson, K.J. Copper-Coated Amorphous Silicon Particles as an Anode Material for Lithium-Ion Batteries. Chem. Mater. 2012, 24, 1306-1315.

13. Thoss, F.; Giebeler, L.; Oswald, S.; Ehrenberg, H.; Eckert, J. Study on the reversible Li-insertion of amorphous and partially crystalline $\mathrm{Al}_{86} \mathrm{Ni}_{8} \mathrm{La}_{6}$ and $\mathrm{Al}_{86} \mathrm{Ni}_{8} \mathrm{Y}_{6}$ alloys as anode materials for Li-ion batteries. J. Electrochim. Acta 2012, 60, 85-94.

14. Zhang, B.; Wang, R.J.; Zhao, D.Q.; Pan, M.X.; Wang, W.H. Superior glass-forming ability through microalloying in cerium-based alloys. Phys. Rev. B 2006, 73, 092201:1-092201:4.

15. Wang, W.H. Roles of minor additions in formation and properties of bulk metallic glasses. Prog. Mater. Sci. 2007, 52, 540-596.

16. Eckert, J.; Das, J.; Pauly, S.; Duhamel, C. Mechanical properties of bulk metallic glasses and composites. J. Mater. Res. 2007, 22, 285-301. 
17. Inoue, A.; Takeuchi, A. Recent development and application products of bulk glassy alloys. Acta Mater. 2011, 59, 2243-2267.

18. Perepezko, J.H.; Hebert, R.J.; Wu, R.I.; Wilde, G. Primary crystallization in amorphous Al-based alloys. J. Non-Cryst. Solids 2003, 317, 52-61.

19. Battezzati, L.; Rizzi, P.; Rontó, V. The difference in devitrification paths in $\mathrm{Al}_{87} \mathrm{Ni}_{7} \mathrm{Sm}_{6}$ and $\mathrm{Al}_{87} \mathrm{Ni}_{7} \mathrm{La}_{6}$ amorphous alloys. Mater. Sci. Eng. A 2004, 375-377, 927-931.

20. Yang, B.J.; Yao, J.H.; Zhang, J.; Yang, H.W.; Wang, J.Q.; Ma, E. Al-rich bulk metallic glasses with plasticity and ultrahigh specific strength. Scr. Mater. 2009, 61, 423-426.

21. Zhu, X.; Schoenitz, M.; Dreizin, E.L. Mechanically alloyed Al-Li powders. J. Alloys Compd. 2007, 432, 111-115.

22. Miracle, D.B.; Louzguine-Luzgin, D.V.; Louzguina-Luzgina, L.V.; Inoue, A. An assessment of binary metallic glasses: Correlations between structure, glass forming ability and stability. Int. Mater. Rev. 2010, 50, 218-256.

23. Schroers, J. Processing of Bulk Metallic Glass. Adv. Mater. 2011, 22, 1566-1597.

24. Moulder, J.F.; Stickle, W.F.; Sobol, P.E.; Bomben, K.D. Handbook of X-ray Photoelectron Spectroscopy; Chastain, J., King, R.C., Jr., Eds.; Physical Electronics, inc.: Eden Prairie, MN, USA, 1995.

25. Oswald, S. Leibniz Institute for Solid State and Materials Research, Dresden, Germany. Personal Communication, 2012.

26. Hoenigman, J.R.; Keil, R.G. An XPS study of the adsorption of oxygen and water-vapor on clean lithium films. Appl. Surf. Sci. 1984, 18, 207-222.

27. Li, J.; Li, J.; Luo, J.; Wang, L.; He, X. Recent advances in the $\mathrm{LiFeO}_{2}$-based materials for $\mathrm{Li}$-ion batteries. Int. J. Electrochem. Soc. 2011, 6, 1550-1561.

28. Shi, L.; He, Y.D.; Xia, X.H.; Jian, Z.M.; Liu, H.B. High rate capability of $\mathrm{Fe} / \mathrm{FeO} / \mathrm{Fe}_{3} \mathrm{O}_{4}$ composite as anode material for lithium-ion batteries. J. Iran. Chem. Soc. 2010, 7, 721-726.

29. Yue, G.Q.; Liu, C.; Wang, D.Z.; Wang, Y.; Yuan, Q.F.; Xu, R.; Zhao, F.G.; Chen, C. Nano-sized Li-Fe composite oxide prepared by a self-catalytic reverse atom transfer radical polymerization approach as an anode material for lithium-ion batteries. Mater. Res. Bull. 2010, 45, 1319-1323.

30. Kazama, A.; Sekine, Y.; Oyama, K.; Matsukata, M.; Kikuchi, E. Promoting effect of small amount of $\mathrm{Fe}$ addition onto Co catalyst supported on $\alpha-\mathrm{Al}_{2} \mathrm{O}_{3}$ for steam reforming of ethanol. Appl. Catal. A 2010, 383, 96-101.

31. Acke, F.; Panas, I. Promoting Effects of $\mathrm{Na}$ and Fe Impurities on the Catalytic Activity of $\mathrm{CaO}$ in the Reduction of $\mathrm{NO}$ by $\mathrm{CO}$ and $\mathrm{H}_{2}$. J. Phys. Chem. B 1998, 102, 5127-5134.

32. Twin, A.J.; Abell, J.S.; Harris, I.R. Evidence of enhanced antiferromagnetism in highly doped $\mathrm{YBa}_{2}\left(\mathrm{Cu}_{1-x} \mathrm{Fe}_{x}\right) 3 \mathrm{O}_{6+y}$. J. Magn. Magn. Mater. 1992, 104, 611-612.

33. Baiker, A.; Bakai, A.S.; Eckert, J.; Fecht, H.J.; Häussler, P.; Johnson, W.L.; Samwer, K.; Schultz, L. Amorphization Techniques, Catalysis, Electronic and Ionic Structure. In Glassy Metal; Beck, H., Güntherodt, H.-J., Eds.; Springer: Berlin, Germany, 1994; Volume 3. 
34. Brand, R. Improving the validity of hyperfine field distiribution from magnetic alloys. 1. Unpolarized source. Nucl. Instrum. Methods Phys. Res. B 1987, 28, 398-416.

(C) 2013 by the authors; licensee MDPI, Basel, Switzerland. This article is an open access article distributed under the terms and conditions of the Creative Commons Attribution license (http://creativecommons.org/licenses/by/3.0/). 